\title{
EXTRAÇÃO E EFICIÊNCIA DE USO DE NUTRIENTES EM CAPIM-ELEFANTE NA PRESENÇA DE GESSO(1)
}

\author{
Renato Lemos dos Santos $^{(2)}$, Vinícius Mendes de Azevedo(3), Fernando \\ José Freire $^{(4)}$, Alexandre Tavares da Rocha( ${ }^{(5)}$, José Alves Tavares ${ }^{(6)} \&$ \\ Maria Betânia Galvão dos Santos Freire ${ }^{(4)}$
}

\begin{abstract}
RESUMO
O cultivo de capim-elefante (Pennisetum purpureum Schum) na região do Polo Gesseiro do Araripe, localizada a oeste do Estado de Pernambuco, no Nordeste do Brasil, pode ser uma alternativa viável de energia, em especial quando se realiza a correção da fertilidade do solo. O objetivo deste trabalho foi avaliar o efeito do gesso no estado nutricional, na composição mineral, na produção de biomassa e na extração e eficiência de nutrientes de variedades de capim-elefante na Chapada do Araripe, Estado de Pernambuco. Para isso, foram cultivadas três variedades de capim-elefante - Cameroon, Gramafante e Roxo - na presença e ausência de gesso em blocos casualizados em arranjo fatorial ( $3 \times 2)$, com quatro repetições. Os capins-elefante Cameroon e Gramafante apresentaram elevadas produções de matéria seca, porém apenas a variedade Cameroon mostrou resposta à aplicação de gesso, tendo alcançado $33 \mathrm{Mg} \mathrm{ha}^{-1}$. O capim-elefante Gramafante foi mais eficiente no uso de Ca que as variedades Cameroon e Roxo.
\end{abstract}

Termos de indexação: gipsita, nutrição vegetal, produção de biomassa vegetal.

(1) Recebido para publicação em 8 de julho de 2011 e aprovado em 19 de dezembro de 2011.

(2) Doutorando do Programa de Pós-Graduação em Ciência do Solo, Universidade Federal Rural de Pernambuco - UFRPE. Rua Dom Manoel de Medeiros s/n, Dois Irmãos, CEP 52171-900 Recife (PE). E-mail: santosrld@gmail.com

(3) Aluno de Graduação do curso de Agronomia, UFRPE. E-mail: vinicius.mendesazevedo@hotmail.com

(4) Professor Associado, UFRPE. E-mail: f.freire@depa.ufrpe.br; betania@depa.ufrpe.br

(5) Professor Adjunto, UFRPE, Unidade Acadêmica de Serra Talhada, Fazenda Saco s/n, Caixa Postal 063, Serra Talhada (PE). E-mail: alexandre@uast.ufrpe.br

(6) Pesquisador do Instituto Agronômico de Pernambuco. Rodovia Araripina-PE 585, km 18, CEP 56280-000 Araripina (PE). E-mail: j.alvestavares@gmail.com 


\title{
SUMMARY: NUTRIENT UPTAKE AND USE EFFICIENCY OF ELEPHANT GRASS IN THE PRESENCE OF CRUDE GYPSUM
}

\begin{abstract}
The cultivation of Elephant or Napier grass (Pennisetum purpureum) in the gypsumproducing region of Araripe, in the west of the state of Pernambuco in northeastern Brazil, may be viable as alternative energy, especially when the soil fertility is improved. The objective of this study was to evaluate the effect of crude gypsum on the nutritional status, mineral composition, biomass production, and nutrient uptake efficiency of elephant grass varieties in Araripe, Pernambuco. For this purpose, three elephant grass varieties: Cameroon, Gramafante and Roxo, were planted in the presence and absence of gypsum in randomized blocks in a factorial arrangement ( $3 \times 2$ ) with four replications. The dry matter production of Cameroon and Gramafante was high, but the response to gypsum was only significant for the variety Cameroon, with $33 \mathrm{Mg} \mathrm{ha}{ }^{-1}$. Gramafante was more efficient in the use of Ca than Cameroon and Roxo.
\end{abstract}

Index terms: Gypsum, plant nutrition, plant biomass production.

\section{INTRODUÇÃO}

A elevada capacidade de produção de matéria seca do capim-elefante (Pennisetum purpureum Schum) pode ser utilizada como biomassa alternativa para produção energética no Sertão do Araripe (Mello et al., 2002; Quesada et al., 2003). Para isso, é necessário pesquisar as relações nutricionais do cultivo do capim-elefante na região do Araripe, principalmente por se tratar de solos ácidos, que exigem correção com calcário em superfície e gesso em subsuperfície (Alvarez V. et al., 1999).

A composição mineral de espécies forrageiras varia em função do tipo de solo e adubações realizadas, das diferenças genéticas entre espécies, variedades, das estações do ano e do intervalo de cortes (Andrade et al., 2000).

As deficiências nutricionais limitantes ao estabelecimento e produção de capim-elefante têm sido associadas a fatores relacionados com acidez do solo, particularmente toxidez de $\mathrm{Al}$, baixa disponibilidade de $\mathrm{Ca}$ e $\mathrm{Mg}$ e deficiência de $\mathrm{P}$ (Quesada, 2005). Nesse contexto encontra-se grande parte dos solos da Chapada do Araripe. Em geral, são Latossolos que apresentam limitações agrícolas em razão dos elevados índices de acidez, tanto em superfície como em subsuperfície (Cavalcanti \& Lopes, 1994).

Para elevar os níveis de Ca e reduzir a saturação por $\mathrm{Al}$ em subsuperfície, faz-se uso de gesso, que pode ser originado da produção do ácido fosfórico, com o nome de fosfogesso (Saldanha et al., 2007), ou oriundo de depósito prevalente sedimentar associado a depósitos evaporíticos (Rodrigues \& Fonseca, 2009).

O uso do gesso produzido na região do Araripe pode potencializar a produção de matéria seca do capim-elefante, por sua atuação na correção da acidez trocável em subsuperfície, proporcionando maior quantidade de biomassa, que pode ser utilizada como fonte de energia alternativa no processo de calcinação da gipsita na indústria gesseira do Araripe. Dessa forma, este trabalho objetivou avaliar o efeito do gesso mineral no estado nutricional, na composição mineral, na produção de biomassa e na extração e eficiência de nutrientes de diferentes variedades de capim-elefante na Chapada do Araripe, em Pernambuco.

\section{MATERIAL E MÉTODOS}

Conduziu-se, no período de janeiro a setembro de 2010, um experimento de campo na Estação Experimental de Araripina, do Instituto Agronômico de Pernambuco (IPA), localizada nas coordenadas geográficas de $07^{\circ} 27^{\prime} 37^{\prime}$ 'S e $40^{\circ} 24^{\prime} 36^{\prime \prime} \mathrm{W}$ e altitude de $831 \mathrm{~m}$, em um solo classificado como Latossolo Amarelo (Cavalcanti \& Lopes, 1994).

A vegetação é basicamente composta por Caatinga Hiperxerófila, com trechos de Floresta Caducifólia. O clima é do tipo tropical semiárido, com chuvas de verão, tendo o período chuvoso início em novembro e término em abril; a precipitação pluvial no período foi de $350,2 \mathrm{~mm}$ (Figura 1).

Os atributos químicos e físicos do solo (Quadro 1) foram determinados em duas profundidades $(0,0$ a 0,2 e 0,2 a $0,4 \mathrm{~m}$ ), nas quais se determinaram o pH $\left(\mathrm{H}_{2} \mathrm{O}\right), \mathrm{pH}\left(\mathrm{CaCl}_{2} 0,01 \mathrm{~mol} \mathrm{~L}{ }^{-1}\right), \mathrm{Ca}^{2+}, \mathrm{Mg}^{2+}$, $\mathrm{K}^{+}, \mathrm{Na}^{+}, \mathrm{Al}^{3+},(\mathrm{H}+\mathrm{Al}), \mathrm{P}$, COT (carbono orgânico total), $\mathrm{S}_{-} \mathrm{SO}_{4}{ }^{2-}$, capacidade máxima de adsorção de sulfato (CMAS) e P-remanescente (P-rem). Exceto o S-SO ${ }_{4}{ }^{2-}$ disponível, a CMAS e o P-rem, que foram determinados segundo Alvarez V. et al. (2001), as demais análises seguiram o método da Embrapa (Silva, 2009). Fisicamente, o solo foi 


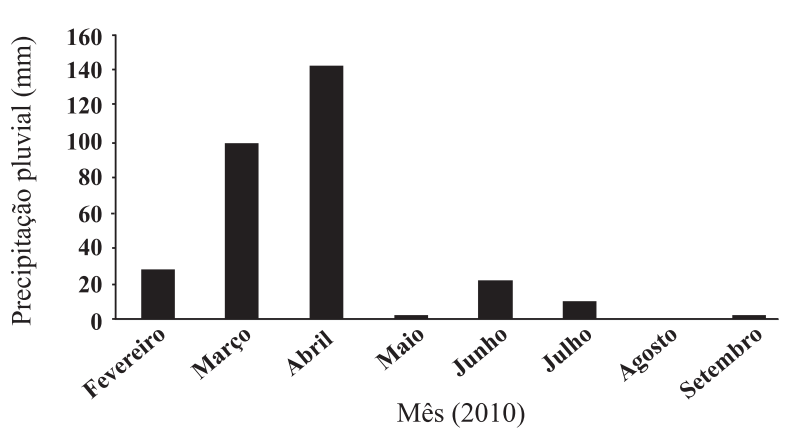

Figura 1. Pluviometria durante o ensaio experimental na Estação Experimental do Instituto Agronômico de Pernambuco, em Araripina/PE.

caracterizado quanto a sua granulometria para definição de sua classe textural; densidade do solo; densidade de partículas; condutividade hidráulica; e, indiretamente, porosidade total. Com exceção da granulometria, determinada pelo método da pipeta adaptado por Ruiz (2005), todas as demais análises físicas foram realizadas de acordo com o método proposto pela Embrapa (1997).

Foram utilizadas três variedades de capimelefante (Roxo, Cameroon e Gramafante), submetidas a duas doses de gesso: 0 e $494 \mathrm{~kg} \mathrm{ha}^{-1}$ (Alvarez V. et al., 1999), aplicadas no fundo do sulco de plantio, a $0,3 \mathrm{~m}$ de profundidade. O ensaio foi disposto em delineamento de blocos casualizados em esquema fatorial $3 \times 2$, em parcela subdividida, com quatro repetições. A subparcela foi composta por sete sulcos de $6 \mathrm{~m}$ de comprimento, espaçados de $1 \mathrm{~m}$, perfazendo uma área total de $42 \mathrm{~m}^{2}$. A área útil foi formada pelas três linhas centrais, descartando $1 \mathrm{~m}$ das extremidades, o que totalizou $12 \mathrm{~m}^{2}$.

O experimento foi instalado no início das chuvas (Figura 1), sendo precedido da aplicação e incorporação, até $0,2 \mathrm{~m}$ de profundidade, de calcário dolomítico a lanço em área total, onde a necessidade de calagem (NC) correspondeu a 0,550 $\mathrm{Mg} \mathrm{ha}^{-1}$ (Cavalcanti, 2008), e da aplicação do gesso. Oito dias após a aplicação dos corretivos, foi feito o plantio das variedades de capim-elefante, com cerca de 4,0 $\mathrm{Mg} \mathrm{ha}^{-1}$ de colmo com três meses de idade, dispostos em duas fileiras, sendo em seguida rebolados em toletes com quatro a cinco gemas, pulverizados com cupinicida; posteriormente, realizou-se o fechamento do sulco.

Todas as parcelas receberam $300 \mathrm{~kg} \mathrm{ha}^{-1}$ de sulfato de amônio (20\% de N), $286 \mathrm{~kg} \mathrm{ha}^{-1}$ de superfosfato triplo $\left(40 \%\right.$ de $\left.\mathrm{P}_{2} \mathrm{O}_{5}\right)$ e $150 \mathrm{~kg} \mathrm{ha}^{-1}$ de cloreto de potássio $\left(60 \%\right.$ de $\left.\mathrm{K}_{2} \mathrm{O}\right)$, calculados de acordo com as Recomendações de Adubação para o Estado de Pernambuco (Cavalcanti, 2008).

Aos 128 dias após o plantio, realizou-se a coleta da folha índice de 10 plantas na parcela
Quadro 1. Caracterização química e física do solo nas profundidades de 0,0 a 0,2 e 0,2 a $0,4 \mathrm{~m}$ na área do ensaio de campo, na Estação Experimental de Araripina do Instituto Agronômico de Pernambuco, em Araripina/PE

\begin{tabular}{|c|c|c|}
\hline \multirow{2}{*}{ Atributo } & \multicolumn{2}{|c|}{ Profundidade } \\
\hline & $0,0-0,2 \mathrm{~m}$ & $0,2-0,4 \mathrm{~m}$ \\
\hline $\mathrm{pH}_{\text {água }}(1: 2,5)$ & 4,85 & 4,54 \\
\hline $\mathrm{pH} \mathrm{CaCl}{ }_{2}(1: 2,5)$ & 3,30 & 3,40 \\
\hline $\mathrm{Ca}^{2+}\left(\mathrm{cmol}_{\mathrm{c}} \mathrm{dm}^{-3}\right)$ & 0,95 & 0,30 \\
\hline $\mathrm{Mg}^{2+}\left(\mathrm{cmol}_{\mathrm{c}} \mathrm{dm}^{-3}\right)$ & 0,68 & 0,38 \\
\hline $\mathrm{K}^{+}\left(\mathrm{cmol}_{\mathrm{c}} \mathrm{dm}^{-3}\right)$ & 0,14 & 0,09 \\
\hline $\mathrm{Na}^{+}\left(\mathrm{cmol}_{\mathrm{c}} \mathrm{dm}^{-3}\right)$ & 0,23 & 0,24 \\
\hline $\mathrm{P}\left(\mathrm{mg} \mathrm{dm}^{-3}\right)$ & 4,00 & 1,00 \\
\hline P-rem $\left(\mathrm{mg} \mathrm{L}^{-1}\right)^{(1)}$ & 62,95 & 58,28 \\
\hline $\mathrm{Al}^{3+}\left(\mathrm{cmol}_{\mathrm{c}} \mathrm{dm}^{-3}\right)$ & 0,37 & 0,70 \\
\hline$(\mathrm{H}+\mathrm{Al})\left(\mathrm{cmol}_{\mathrm{c}} \mathrm{dm}^{-3}\right)$ & 3,74 & 3,27 \\
\hline $\operatorname{COT}\left(\mathrm{g} \mathrm{kg}^{-1}\right)^{(2)}$ & 8,1 & 5,2 \\
\hline $\mathrm{S}-\mathrm{SO}_{4}^{-2}\left(\mathrm{mg} \mathrm{dm}^{-3}\right)$ & 1,83 & 0,69 \\
\hline CMAS $\left(\mathrm{mg} \mathrm{g}^{-1}\right)^{(3)}$ & 0,012 & 0,018 \\
\hline $\mathrm{CTC}_{\text {efetiva }}\left(\mathrm{cmol}_{\mathrm{c}} \mathrm{dm}^{-3}\right)^{(4)}$ & 2,37 & 1,71 \\
\hline $\mathrm{m}(\%)^{(5)}$ & 15,49 & 40,90 \\
\hline $\mathrm{V}(\%)^{(6)}$ & 84,39 & 59,06 \\
\hline $\operatorname{PST}(\%)^{(7)}$ & 3,95 & 5,49 \\
\hline Areia Total $\left(\mathrm{g} \mathrm{kg}^{-1}\right)$ & 730 & 722 \\
\hline Areia Grossa (g kg-1) & 570 & 551 \\
\hline Areia Fina $\left(\mathrm{g} \mathrm{kg}^{-1}\right)$ & 160 & 171 \\
\hline Silte $\left(\mathrm{g} \mathrm{kg}^{-1}\right)$ & 134 & 144 \\
\hline Argila (g kg-1) & 136 & 134 \\
\hline Classe textural & Franco-arenosa & Franco-arenosa \\
\hline $\mathrm{Dp}\left(\mathrm{kg} \mathrm{dm}^{-3}\right)^{(8)}$ & 2,99 & 2,98 \\
\hline Ds $\left(\mathrm{kg} \mathrm{dm}^{-3}\right)^{(9)}$ & 1,43 & 1,41 \\
\hline PT (\%) $)^{(10)}$ & 52,26 & 52,64 \\
\hline $\mathrm{K}_{0}\left(\mathrm{~mm} \mathrm{~h}^{-1}\right)^{(11)}$ & 65,24 & 92,83 \\
\hline
\end{tabular}

(1) Fósforo remanescente. ${ }^{(2)}$ Carbono orgânico total. ${ }^{(3)}$ Capacidade máxima de adsorção de sulfato. ${ }^{(4)}$ Capacidade de troca de cátions. (5) Saturação por alumínio. ${ }^{(6)}$ Saturação por bases. ${ }^{(7)}$ Porcentagem de sódio trocável. ${ }^{(8)}$ Densidade de partícula. ${ }^{(9)}$ Densidade do solo. ${ }^{(10)}$ Porosidade total. ${ }^{(11)}$ Condutividade hidráulica saturada.

útil. Considerou-se como folha-índice a folha +3 - recém-madura (Cavalcanti, 2008). As referidas folhas tiveram sua nervura central e extremidades removidas.

O corte e a avaliação das variedades de capimelefante foram realizados aos 213 dias após o plantio. Foram coletadas 10 plantas aleatoriamente na parcela útil, sendo posteriormente pesadas e trituradas em forrageira. Tanto as folhas +3 quanto uma subamostra da biomassa foram secas em estufa 
de circulação forçada de ar a $65^{\circ} \mathrm{C}$, até atingirem peso constante, sendo posteriormente trituradas e acondicionadas em sacos plásticos. Com base no número de perfilhos por metro linear, foi possível estimar a produção da parcela útil, corrigindo as falhas da brotação do material utilizado no plantio.

Foi realizada digestão nítrico-perclórica das amostras da folha-diagnóstico e da subamostra da biomassa. Em seguida, foram determinados os teores de Ca e Mg por espectrometria de absorção atômica; $\mathrm{K}$, por fotometria de chama; $\mathrm{P}$, por colorimetria; e $\mathrm{S}$, por turbidimetria. Todas as determinações seguiram os procedimentos recomendados pela Embrapa (Silva, 2009). Com os teores de nutrientes da folhadiagnóstico, foi possível avaliar o estado nutricional das diferentes variedades de capim-elefante. Pelo produto do teor de nutrientes da biomassa e a produção de matéria seca foi obtida a quantidade extraída de nutrientes pelas variedades de capimelefante. A eficiência nutricional, de cada nutriente, foi calculada pela razão entre a produção de matéria seca e a quantidade de nutriente extraída.

Os dados das variáveis de planta foram submetidos à análise da variância (ANOVA) pelo teste $F(p \leq 0,05)$. Nas variáveis cujos efeitos principais e, ou, interação foram significativos, aplicou-se o teste de comparação de médias de Tukey $(\mathrm{p} \leq 0,05)$.

\section{RESULTADOS E DISCUSSÃO}

Os teores de $\mathrm{Mg}$ e $\mathrm{K}$ deste trabalho situaramse na faixa de suficiência (Silva, 2009). Os teores de Ca na folha +3 (Quadro 2) foram maiores que os apresentados por Silva (2009), possivelmente devido à adição considerável de Ca pela calagem e gessagem. O maior valor foi observado na variedade Gramafante, sendo diferente das variedades Roxo e Cameroon, as quais foram semelhantes (Quadro 2).

Os teores de Ca, Mg K, P e S na folha +3 do capimelefante não foram influenciados pela aplicação de gesso (Quadros 2 e 3). Assim, constata-se que não houve acúmulo desses nutrientes com a aplicação do insumo.

Em todas as variedades, os teores de P (Quadro 3) situaram-se dentro da faixa de suficiência para capim-elefante (Silva, 2009), mesmo com os teores iniciais de $\mathrm{P}$ no solo sendo considerados baixos (Quadro 1), conforme Cavalcanti (2008), indicando resposta satisfatória à aplicação de superfosfato triplo.

No capim Cameroon, constatou-se que o teor de $P$ na folha +3 foi menor nas plantas que receberam gesso (Quadro 3). É provável que, mesmo com o deslocamento de $\mathrm{P}$ pelo $\mathrm{S}_{-} \mathrm{SO}_{4}{ }^{2-}$ no solo, essa variedade tenha apresentado preferência de absorção de $\mathrm{S}_{-} \mathrm{SO}_{4}{ }^{2-}$ em relação ao $\mathrm{P}$. Observou-se na ausência de gesso, o $\mathrm{P}$ passou a ser mais absorvido, resultando no aumento de seu teor na folha +3 , sendo com que o capim Cameroon a variedade que mais apresentou $\mathrm{P}$ na folha +3 na ausência de gesso (Quadro 3).

Os teores de $\mathrm{S}$ na folha +3 das variedades de capim-elefante ficaram cerca de duas vezes acima do teor apresentado por Silva (2009) para um adequado estado nutricional (Quadro 3). No ensaio utilizou-se sulfato de amônio como fonte de N, o que impactou a maior disponibilidade de $\mathrm{S}_{-} \mathrm{SO}_{4}{ }^{2-}$ no solo, favorecendo a absorção do nutriente. Entretanto, a aplicação de gesso não interferiu no teor de $\mathrm{S}$ na folha +3 nas variedades de capim-elefante (Quadro 3). É provável

Quadro 2. Teor de cálcio, magnésio e potássio na folha +3 em três variedades de capim-elefante, na presença e ausência de gesso, aos 128 dias após o plantio, média, análise de variância e coeficiente de variação das variáveis

\begin{tabular}{|c|c|c|c|c|c|c|c|c|c|}
\hline \multirow{2}{*}{ Capim } & \multicolumn{2}{|c|}{ Cálcio } & \multirow{2}{*}{ Média } & \multicolumn{2}{|c|}{ Magnésio } & \multirow{2}{*}{ Média } & \multicolumn{2}{|c|}{ Potássio } & \multirow{2}{*}{ Média } \\
\hline & C/gesso & S/gesso & & C/gesso & S/gesso & & C/gesso & S/gesso & \\
\hline & & & & & $\mathrm{g} \mathrm{kg}^{-1}$ & & & & \\
\hline Cameroon & 16,70 & 13,99 & $15,34 \mathrm{~b}$ & 1,54 & 1,80 & $1,67 \mathrm{a}$ & 22,69 & 26,98 & $24,83 \mathrm{a}$ \\
\hline Gramafante & 20,49 & 17,81 & $19,15 \mathrm{a}$ & 1,58 & 1,92 & $1,75 \mathrm{a}$ & 22,07 & 25,07 & $23,57 \mathrm{a}$ \\
\hline Roxo & 15,70 & 16,52 & $16,11 b$ & 1,69 & 1,51 & $1,60 \mathrm{a}$ & 27,05 & 27,10 & $27,07 \mathrm{a}$ \\
\hline \multirow[t]{2}{*}{ Média } & $17,63 \mathrm{~A}$ & $16,11 \mathrm{~A}$ & & $1,60 \mathrm{~A}$ & $1,75 \mathrm{~A}$ & & $23,94 \mathrm{~A}$ & $26,38 \mathrm{~A}$ & \\
\hline & \multicolumn{9}{|c|}{ Teste de F } \\
\hline \multirow{3}{*}{$\begin{array}{l}\text { Capim } \\
\text { Gesso } \\
\text { Capim*Gesso }\end{array}$} & \multicolumn{2}{|c|}{$9,99 *$} & & \multicolumn{2}{|c|}{$0,24^{\mathrm{ns}}$} & \multicolumn{4}{|c|}{$1,38^{\mathrm{ns}}$} \\
\hline & \multicolumn{2}{|c|}{$4,28 \mathrm{~ns}$} & & \multicolumn{2}{|c|}{$0,68^{\mathrm{ns}}$} & \multicolumn{4}{|c|}{$1,97 \mathrm{~ns}$} \\
\hline & \multicolumn{2}{|c|}{$2,52^{\mathrm{ns}}$} & & \multicolumn{2}{|c|}{$0,89^{\text {ns }}$} & \multicolumn{4}{|c|}{$0,52^{\mathrm{ns}}$} \\
\hline PV (0) Parcela & \multicolumn{2}{|c|}{10,15} & & \multicolumn{2}{|c|}{16,94} & \multicolumn{4}{|c|}{22,82} \\
\hline CV (\%) Subparcela & \multicolumn{2}{|c|}{10,68} & & \multicolumn{2}{|c|}{25,29} & \multicolumn{3}{|c|}{16,95} & \\
\hline
\end{tabular}

Letras maiúsculas iguais na linha e minúsculas na coluna não diferem (Tukey, $\mathrm{p} \leq 0,05$ ). 
Quadro 3. Teor de fósforo e enxofre na folha +3 em três variedades de capim-elefante, na presença e ausência de gesso, aos 128 dias após o plantio, média, análise de variância e coeficiente de variação das variáveis

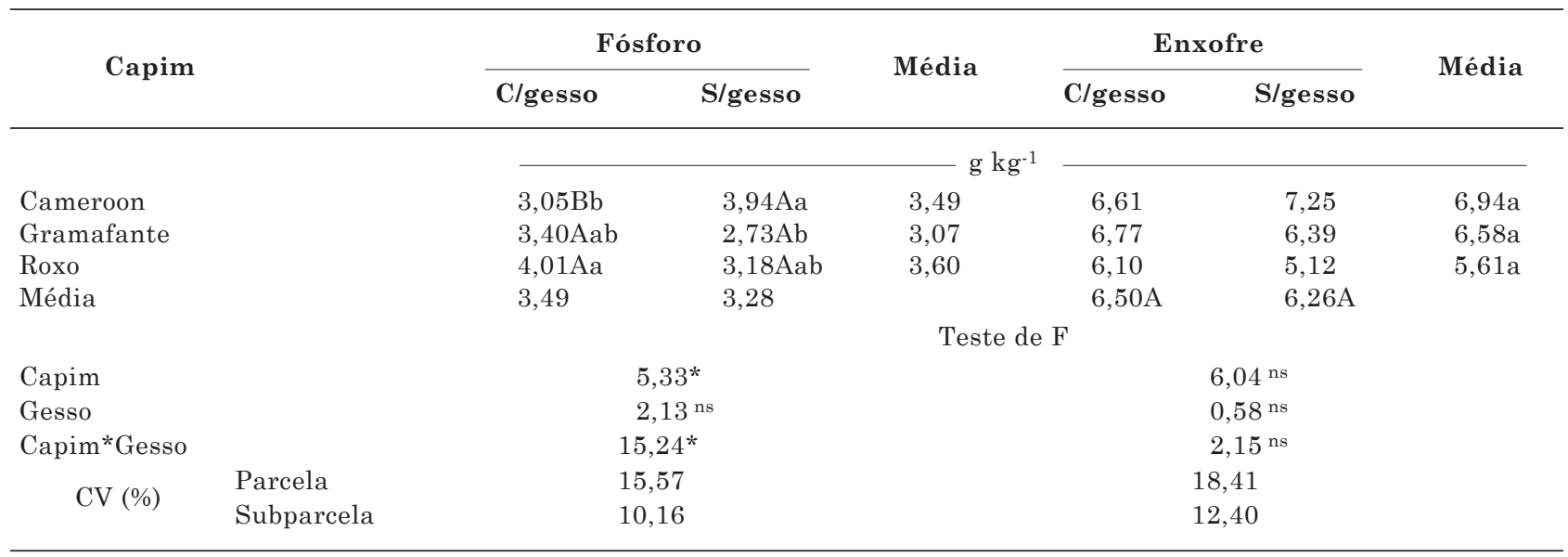

Letras maiúsculas iguais na linha e minúsculas na coluna não diferem (Tukey, $\mathrm{p}<0,05)$.

que quantidade significativa de $\mathrm{S}_{-} \mathrm{SO}_{4}{ }^{2-}$ tenha sido lixiviada para além dos $0,4 \mathrm{~m}$ de profundidade do perfil do solo, em razão das elevadas precipitações pluviais que ocorreram logo após a aplicação do gesso (Figura 1). Dessa forma, a quantidade de $\mathrm{S}_{-} \mathrm{SO}_{4}{ }^{2-}$ remanescente que permaneceu no solo não proporcionou diferenciação no teor de $\mathrm{S}$ da folha +3 nas diferentes variedades de capim-elefante (Quadro 3).

A aplicação de gesso promoveu aumento na produção de matéria fresca apenas da variedade Cameroon (Figura 2a), com ganho relativo de $23 \mathrm{Mg} \mathrm{ha}{ }^{-1}$. Na presença de gesso, as produções de matéria fresca das variedades Cameroon, Gramafante e Roxo mostraram-se diferentes (Figura 2a). Contudo, na ausência do insumo, as variedades Cameroon e Gramafante apresentaram semelhantes produções de matéria fresca-maiores que a apresentada pela variedade Roxo. Caíres et al. (2004), estudando o efeito do gesso na produção de milho, encontraram efeito positivo na produção de grãos com o aumento da dose, corroborando os resultados deste trabalho.

A aplicação do gesso proporcionou aumento de $9 \mathrm{Mg}$ ha $^{-1}(37,5 \%)$ na produção de matéria seca na variedade Cameroon, porém não provocou alterações significativas na produção das variedades Gramafante e Roxo (Figura 2b). Na presença do gesso, as variedades Cameroon e Gramafante apresentaram produções de matéria seca diferentes daquelas da variedade Roxo. A maior produção foi observada na variedade Cameroon, com $33 \mathrm{Mg} \mathrm{ha}^{-1}$. $\mathrm{Na}$ ausência do insumo, a produção de matéria seca das variedades Cameroon e Gramafante foi semelhante (Figura 2b). Dessa forma, a variedade de capim-elefante Cameroon teve sua produção de matéria seca potencializada pelo gesso.
Guedes et al. (2000) relataram aumento de $29 \%$ na produção de matéria seca com adição de gesso em braquiária quando aplicaram $0,5 \mathrm{Mg} \mathrm{ha}^{-1}$ - dose próxima à utilizada neste trabalho. Na maior dose (1,5 $\left.\mathrm{Mg} \mathrm{ha}^{-1}\right)$, esses autores constataram aumento de $46 \%$ na produção de matéria seca.

A variedade de capim-elefante Cameroon apresentou menor teor de Ca quando recebeu gesso

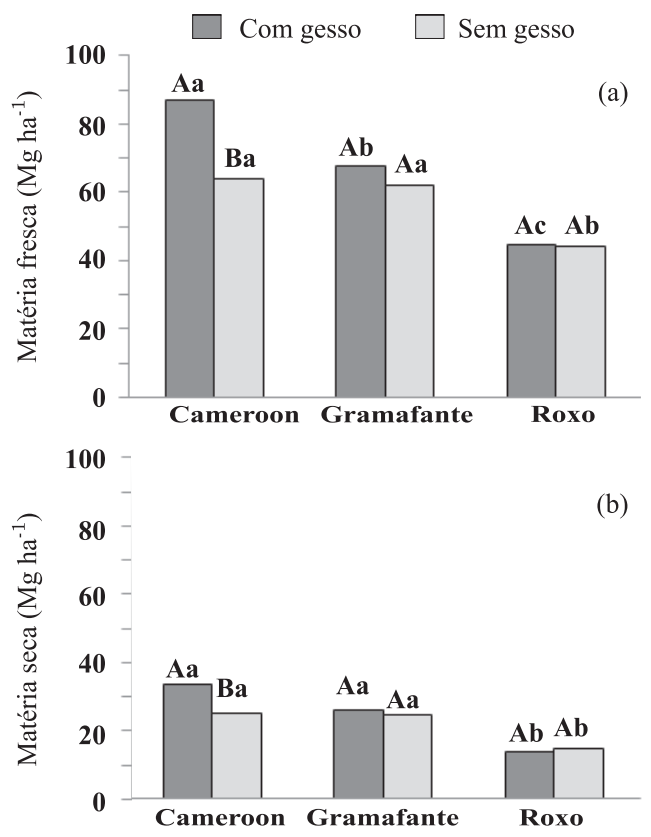

Figura 2. Produção de matéria fresca (a) e seca (b) de três variedades de capim-elefante, na presença e ausência de gesso. Letras maiúsculas comparam a presença e ausência de gesso dentro de cada variedade, e letras minúsculas, as variedades na presença e ausência de gesso. Letras iguais não diferem (Tukey, $p \leq 0,05$ ). 
(Quadro 4), devido, provavelmente, à maior produção de matéria seca dessa variedade na presença de gesso (Figura 2b). O capim-elefante Roxo foi a variedade que apresentou os maiores teores de Ca na biomassa, independentemente da aplicação de gesso (Quadro 4). Quando se analisam os dados do teor de Ca nos capins Gramafante e Roxo em função da aplicação de gesso, percebe-se que os teores de Ca na presença e na ausência do insumo são semelhantes (Quadro 4), corroborando os valores de produção de matéria seca semelhantes (Figura 2b).

Maior teor de $\mathrm{Mg}$ na biomassa foi constatado na variedade Roxo (Quadro 4). Valores semelhantes a esses foram obtidos por Quesada (2005), porém superiores aos de Bernardino et al. (2005), ao analisarem a composição bromatológica do capimelefante e da casca de café utilizados na ensilagem.

A aplicação de gesso não alterou os teores de $\mathrm{Mg}, \mathrm{K}, \mathrm{P}$ e $\mathrm{S}$ na biomassa aérea em nenhuma das variedades de capim-elefante (Quadros 4 e 5).

Em relação ao teor de $\mathrm{K}$ na biomassa aérea das variedades de capim-elefante, os maiores valores foram encontrados nas variedades Roxo e Cameroon. Os teores de $\mathrm{K}$ encontrados neste trabalho são inferiores aos observados por Obeid et al. (1984) na variedade Mineiro, provavelmente

Quadro 4. Teor de cálcio, magnésio e potássio na parte aérea de três variedades de capim-elefante, na presença e ausência de gesso, aos 213 dias após o plantio, média, análise de variância e coeficiente de variação das variáveis

\begin{tabular}{|c|c|c|c|c|c|c|c|c|c|}
\hline \multirow{2}{*}{ Capim } & \multicolumn{2}{|c|}{ Cálcio } & \multirow{2}{*}{ Média } & \multicolumn{2}{|c|}{ Magnésio } & \multirow{2}{*}{ Média } & \multicolumn{2}{|c|}{ Potássio } & \multirow{2}{*}{ Média } \\
\hline & C/gesso & S/gesso & & C/gesso & S/gesso & & C/gesso & S/gesso & \\
\hline & & & & & $\mathrm{g} \mathrm{kg}^{-1}$ & & & & \\
\hline Cameroon & $4,91 \mathrm{Aa}$ & $10,45 \mathrm{Aa}$ & 7,68 & 1,04 & 2,01 & $1,52 \mathrm{~b}$ & 12,85 & 12,72 & $12,79 \mathrm{a}$ \\
\hline Gramafante & $7,74 \mathrm{Aa}$ & $6,23 \mathrm{Aa}$ & 6,99 & 1,67 & 1,78 & $1,72 \mathrm{~b}$ & 11,76 & 11,11 & $11,43 \mathrm{~b}$ \\
\hline Roxo & $10,37 \mathrm{Aa}$ & $11,32 \mathrm{Aa}$ & 10,84 & 4,33 & 4,14 & $4,24 \mathrm{a}$ & 14,34 & 16,28 & $15,31 \mathrm{a}$ \\
\hline \multirow[t]{2}{*}{ Média } & 7,67 & 9,33 & & $2,35 \mathrm{~A}$ & $2,64 \mathrm{~A}$ & & $12,98 \mathrm{~A}$ & $13,37 \mathrm{~A}$ & \\
\hline & \multicolumn{9}{|c|}{ Teste de F } \\
\hline Capim & \multicolumn{3}{|c|}{$6,52^{*}$} & \multicolumn{3}{|c|}{$67,16^{*}$} & \multicolumn{3}{|c|}{$8,75^{*}$} \\
\hline Gesso & \multicolumn{3}{|c|}{$3,18^{\mathrm{ns}}$} & \multicolumn{3}{|c|}{$1,93^{\mathrm{ns}}$} & \multicolumn{3}{|c|}{$0,25^{\mathrm{ns}}$} \\
\hline Capim*Gesso & \multicolumn{3}{|c|}{$4,94^{*}$} & \multicolumn{3}{|c|}{$2,68^{\mathrm{ns}}$} & \multicolumn{3}{|c|}{$1,06^{\mathrm{ns}}$} \\
\hline \multirow{2}{*}{$\begin{array}{ll}\text { CV (\%) } & \text { Parcela } \\
\text { Subparcela }\end{array}$} & \multicolumn{3}{|c|}{26,07} & \multicolumn{3}{|c|}{20,48} & \multicolumn{3}{|c|}{27,43} \\
\hline & \multicolumn{3}{|c|}{26,81} & \multicolumn{2}{|r|}{20,92} & & \multicolumn{3}{|c|}{14,29} \\
\hline
\end{tabular}

Letras maiúsculas iguais na linha e minúsculas na coluna não diferem (Tukey, $\mathrm{p} \leq 0,05$ ).

Quadro 5. Teor de fósforo e enxofre na parte aérea de três variedades de capim-elefante, na presença e ausência de gesso, aos 213 dias após o plantio, média, análise de variância e coeficiente de variação das variáveis

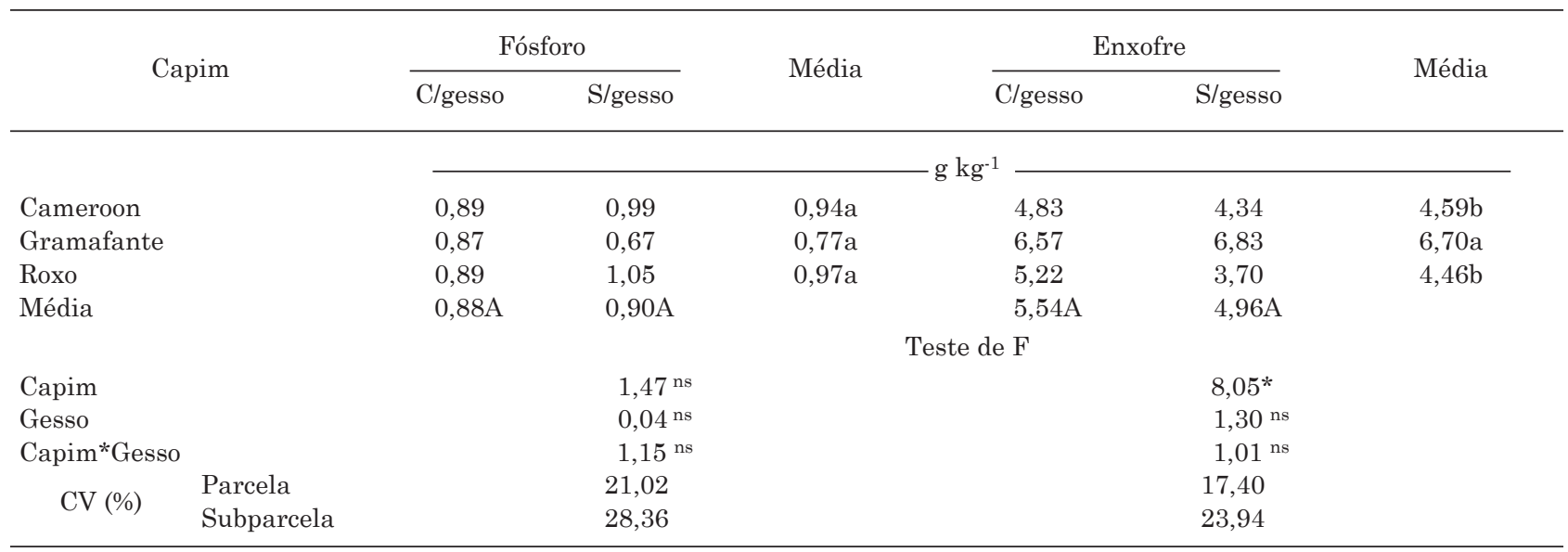

Letras maiúsculas iguais na linha e minúsculas na coluna não diferem (Tukey, $\mathrm{p}<0,05)$. 
devido a diferentes comportamentos genotípicos, uma vez que foi adicionado K, conforme o Manual de Recomendações de Adubação para o Estado de Pernambuco (Cavalcanti, 2008).

Diferentemente dos demais nutrientes, maior teor de $\mathrm{S}$ foi observado na biomassa produzida pela variedade Gramafante, que diferenciou das variedades Cameroon e Roxo, as quais por sua vez foram semelhantes (Quadro 5). É possível que, genotipicamente, o capim Gramafante apresente maior demanda por S do que o Cameroon e o Roxo.

Os valores dos teores de S na biomassa da parte aérea determinados neste trabalho estão acima dos encontrados por Avalhaes et al. (2009), chegando a ser cerca de três vezes maior na variedade Gramafante. Além da gessagem, a adubação com sulfato de amônio também foi responsável pela elevada adição de $\mathrm{S}$ ao solo, elevando sua disponibilidade e, consequentemente, maior absorção, impactando os elevados teores encontrados na biomassa da parte aérea, sobretudo na variedade Gramafante.

A aplicação de gesso não influenciou a extração de $\mathrm{Ca}, \mathrm{Mg}, \mathrm{K}, \mathrm{P}$ e S do solo, independentemente das variedades de capim-elefante. De maneira geral, as variedades de capim-elefante extraíram mais $\mathrm{K}$ do que os outros nutrientes (Figura 3), o que mostra a elevada demanda por $\mathrm{K}$ das gramíneas forrageiras, indicando que a nutrição potássica é fundamental para um adequado programa de fertilização do capim-elefante. A variedade que extraiu maior quantidade de $\mathrm{K}$ foi a Cameroon, devido à elevada produção de matéria seca (Figura $2 \mathrm{~b}$ ), sendo diferente da quantidade extraída pela variedade Roxo, porém ambas apresentaram extração semelhante à da variedade Gramafante (Figura 3).

$\mathrm{O} \mathrm{P}$ foi o nutriente menos extraído pelas variedades de capim-elefante (Figura 3 ). A variedade que mais extraiu $\mathrm{P}$ foi a Cameroon, e a que menos extraiu foi a Roxo, porém ambas apresentaram extrações semelhantes à da variedade Gramafante (Figura 3). Essa diferença de extração de P entre as variedades deveu-se à produção de matéria seca (Figura 2b), uma vez que os teores desse nutriente na biomassa não se diferenciaram (Quadro 5).

A elevada extração de $\mathrm{S}$ pelas variedades de capim-elefante (Figura 3) sugere a sua introdução nos programas de fertilização dessas gramíneas (Quadro 3). Diferentemente do K e P, a maior extração de S ocorreu no capim Gramafante, diferindo das variedades Cameroon e Roxo, respectivamente. Corroboram essa elevada extração de S pela variedade Gramafante os elevados teores de S em sua biomassa (Quadro 5) e sua produção de matéria seca (Figura 2b).

Obeid et al. (1984), ao avaliarem o efeito da adubação sobre a produtividade e o valor nutritivo de capim-elefante Mineiro, observaram remoções de $30 \mathrm{~kg} \mathrm{ha}^{-1}$ de P, $400 \mathrm{~kg} \mathrm{ha}^{-1}$ de K, $54 \mathrm{~kg} \mathrm{ha}^{-1}$ de Ca e $52 \mathrm{~kg} \mathrm{ha}^{-1}$ de $\mathrm{Mg}$ para uma produção de matéria seca de 21,6 Mg ha-1 $\mathrm{ano}^{-1}$. Dessa forma, as quantidades extraídas de $\mathrm{P}$ e $\mathrm{Mg}$ registradas por Obeid et al. (1984) foram próximas das encontradas neste trabalho, enquanto a extração de $\mathrm{K}$ foi maior e a de Ca menor.

O gesso promoveu aumento da eficiência de utilização de $\mathrm{Ca}$ apenas na variedade Cameroon. $\mathrm{Na}$ ausência do insumo, a maior eficiência no uso foi observada na variedade Gramafante (Figura 4).

Os dados de eficiência de utilização de $\mathrm{Ca}$ indicaram que a variedade Gramafante é tão eficiente na ausência de gesso quanto a Cameroon na presença do insumo (Figura 4). Essa elevada eficiência na utilização de $\mathrm{Ca}$ pela variedade Gramafante foi devido a não ter havido redução na produção de matéria seca na ausência de gesso em

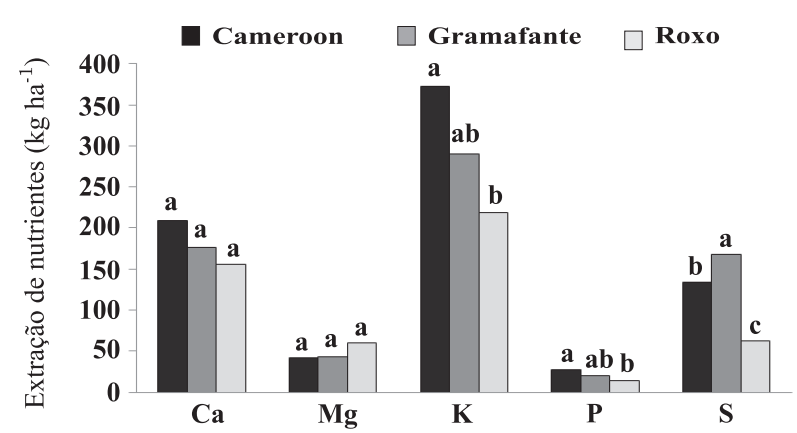

Figura 3. Extração de cálcio, magnésio, potássio, fósforo e enxofre por três variedades de capim-elefante. Letras minúsculas comparam as variedades para cada nutriente. Letras minúsculas iguais não diferem (Tukey, $\mathbf{p} \leq 0,05)$.

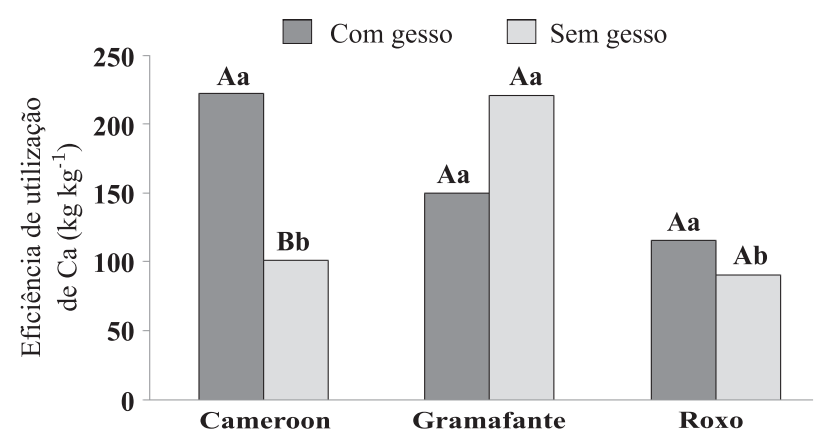

Figura 4. Eficiência de utilização de cálcio por três variedades de capim-elefante, na presença e ausência de gesso. Letras maiúsculas comparam a presença e ausência de gesso dentro de cada variedade, e letras minúsculas comparam as variedades na presença e ausência de gesso. Letras iguais não diferem (Tukey, p $\leq 0,05$ ). 
relação à presença do insumo (Figura 2b), aliada à redução na extração de $\mathrm{Ca}$, de maneira geral, na ausência do insumo, sugerindo que em ambientes com baixos teores de $\mathrm{Ca}$ a indicação para cultivo da variedade Gramafante é recomendável.

Quesada (2005) encontrou maiores produções de matéria seca com a absorção de Ca nas variedades Cameroon, Gramafante e Roxo, que apresentaram eficiência de utilização de 263, 208 e $294 \mathrm{~kg} \mathrm{~kg}^{-1}$, respectivamente. Essas eficiências foram maiores do que as encontradas neste trabalho.

A eficiência de utilização de $\mathrm{Mg}, \mathrm{K}, \mathrm{P}$ e S não foi influenciada nem pela aplicação de gesso nem pela variedade de capim-elefante, com exceção do $\mathrm{Mg}$ e $\mathrm{S}$ (Figura 5).

A eficiência de utilização de $\mathrm{Mg}$ foi maior nas variedades Cameroon e Gramafante, sendo diferentes da variedade Roxo (Figura 5). Entretanto, para a eficiência de utilização de $\mathrm{Mg}$, os valores encontrados por Quesada (2005) foram menores que os observados neste trabalho, tendo o capim Cameroon apresentado eficiência de utilização 2,4 vezes menor.

A menor eficiência de utilização de $\mathrm{S}$ foi observada na variedade Gramafante, sendo diferente da eficiência apresentada pelas variedades Cameroon e Roxo, que foram semelhantes. Essa menor eficiência apresentada pela variedade Gramafante deveu-se à maior extração de enxofre (Figura 3 ), sem conversão em massa de matéria seca (Figura $2 b$ ).

Assim, se por um lado o capim Gramafante está sendo recomendado para ambientes com disponibilidade restrita de $\mathrm{Ca}$ e $\mathrm{Mg}$, deve ser observada em sua nutrição a importância do S, principalmente pela elevada demanda apresentada pelo Gramafante por esse nutriente. Na região

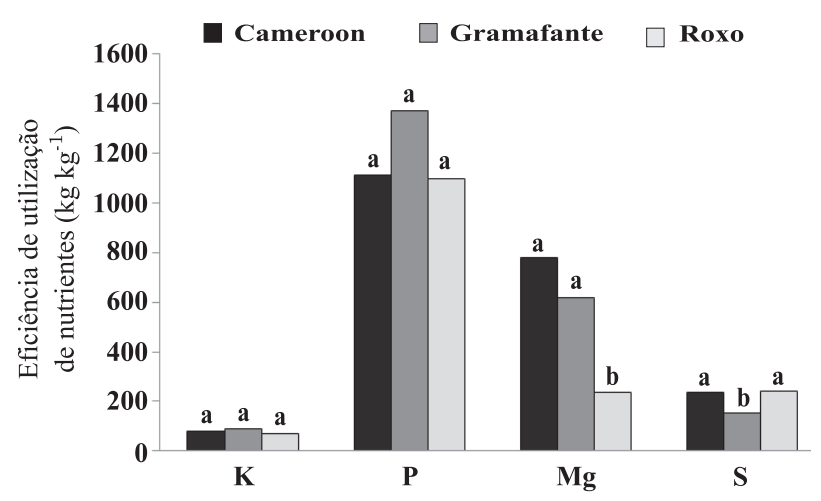

Figura 5. Eficiência de utilização de potássio, fósforo, magnésio e enxofre por três variedades de capim-elefante aos 213 dias após o plantio. Letras minúsculas comparam as variedades para cada nutriente. Letras minúsculas iguais não diferem (Tukey, $\mathbf{p} \leq \mathbf{0 , 0 5}$ ). do Araripe, a abundância de gesso, que contém considerável quantidade de S, viabiliza a indicação desse capim para cultivo como fonte alternativa de energia na calcinação da gipsita.

\section{CONCLUSÕES}

1. Os capins-elefante Cameroon e Gramafante apresentaram elevadas produções de matéria seca, porém apenas a primeira variedade apresentou resposta à aplicação de gesso, sendo essa prática possivelmente viável, porque é um produto de larga produção na região.

2. O capim-elefante Gramafante pode ser recomendado para ambientes restritivos à disponibilidade de Ca e $\mathrm{Mg}$ e férteis em $\mathrm{S}$.

\section{AGRADECIMENTOS}

Ao Programa de Pós-Graduação em Ciência do Solo da UFRPE, à FACEPE, ao CNPq e ao IPA, pelo apoio no financiamento e na realização da pesquisa.

\section{LITERATURA CITADA}

ALVAREZ V., V.H.; DIAS, L.E.; RIBEIRO JÚNIOR, E.S. \& SOUZA, R.B. Uso de gesso agrícola. In: RIBEIRO, A.C.; GUIMARÃES, P.T.G. \& ALVAREZ V., V.H., eds. Recomendações para o uso de corretivos e fertilizantes em Minas Gerais, $5^{\mathrm{a}}$ aproximação. Viçosa, MG, Universidade Federal de Viçosa, 1999. p.67-78.

ALVAREZ V., V.H.; DIAS, L.E.; RIBEIRO JÚNIOR, E.S.; SOUZA, R.B. \& FONSECA, C.A. Métodos de análises de enxofre em solos e plantas. Viçosa, MG, Universidade Federal de Viçosa, 2001. 131p.

ANDRADE, A.C.; FONSECA, D.M.; GOMIDE, J.A.; ALVAREZ V., V.H.; MARTINS, C.E. \& SOUZA, D.P.H. Produtividade e valor nutritivo do capim-elefante cv. napier sob doses crescentes de nitrogênio e potássio. R. Bras. Zootec., 29:1589-1595, 2000.

AVALHAES, C.C.; PRADO, R.M.; ROZANE, D.E.; ROMUALDO, L.M. \& CORREIA, M.A.R. Omissão de macronutrientes no crescimento e no estado nutricional de capim-elefante (cv. Mott) cultivado em solução nutritiva. R. Bras. Ci. Agr., 10:215-222, 2009.

BERNARDINO, F.S.; GARCIA, R.; ROCHA, F.C.; SOUZA, A.L. \& PEREIRA, O.G. Produção e características do efluente e composição bromatológica da silagem de capim-elefante contendo diferentes níveis de casca de café. R. Bras. Zootec., 34:2185-2191, 2005. (Supl.) 
CAÍRES, E.F.; KUSMAN, M.T.; BARTH, G.; GARBUIO, F.J. \& PADILHA, J.M. Alterações químicas do solo e resposta do milho à calagem e aplicação de gesso. R. Bras. Ci. Solo, 28:125-136, 2004.

CAVALCANTI, A.C. \& LOPES, O.F. Condições edafoclimáticas da Chapada do Araripe e viabilidade de produção sustentável de culturas. Brasília, Embrapa, 1994. 42p.

CAVALCANTI, F.J.A., coord. Recomendações de adubação para o Estado de Pernambuco: $2^{a}$ aproximação. 3.ed. Recife, IPA, 2008. 212p.

EMPRESA BRASILEIRA DE PESQUISA AGROPECUÁRIA EMBRAPA. Manual de métodos de análises de solos. 2.ed. Rio de Janeiro, 1997. 212p.

GUEDES, L.M.; GRAÇA, D.S.; MORAIS, M.G.; ANTUNES, R.C. \& GONÇALVES, L.C. Influência da aplicação de gesso na produção de matéria seca, na relação nitrogênio:enxofre e concentrações de enxofre, cobre, nitrogênio e nitrato em pastagens de Brachiaria decumbens Stapf. R. Bras. Med. Veter. Zootec., 52:521-526, 2000.

MELLO, A.C.L.; LIRA, M.A.; DUBEUX JÚNIOR, J.C.B.; SANTOS, M.V.F. \& FREITAS, E.V. Caracterização e Seleção de Clones de Capim-Elefante (Pennisetum purpureum Schum.) na Zona da Mata de Pernambuco. R. Bras. Zootec., 31:30-42, 2002.

OBEID, J.A.; GOMIDE, J.A. \& COMASTRI FILHO, J.A. Efeito da adubação sobre a produtividade e valor nutritivo do capim-elefante 'Mineiro' cultivado em solo sob vegetação de cerrado. R. Soc. Bras. Zootec., 13:488-500, 1984.
QUESADA, D.M.; COELHO, C.H.M.; BODDEY, R.; REIS, V.M.; ALVES, B. \& URQUIAGA, S. Efeito da adubação verde e n-fertilizante no acúmulo de Biomassa e fixação biológica de nitrogênio em genótipos de Capim-elefante (Pennisetum purpureum Schum.). Agronomia, 37:54-59, 2003.

QUESADA, D.M. Parâmetros quantitativos e qualitativos de diferentes genótipos de capim-elefante como potencial para uso energético. Seropédica, Universidade Federal Rural do Rio de Janeiro, 2005. 76p. (Tese de Doutorado)

RODRIGUES, A.F.S. \& FONSECA, D.S. Cimento. In: RODRIGUES, A.F.S., coord. Economia mineral do Brasil. Brasília, DNPM, 2009. p.636-654.

RUIZ, H.A. Incremento da exatidão da análise granulométrica do solo por meio da coleta da suspensão (Silte + Argila). R. Bras. Ci. Solo, 29:297-300, 2005.

SALDANHA, E.C.M.; ROCHA, A.T.; OLIVEIRA, E.C.A.; NASCIMENTO, C.W.A. \& FREIRE, F.J. Uso do gesso mineral em Latossolo cultivado com cana-de-açúcar. R. Caatinga, 20:36-42, 2007.

SILVA, F.C., ed. Manual de análises químicas de solos, plantas e fertilizantes. 2.ed. Brasília, Embrapa Informação Tecnológica/Rio de Janeiro, Embrapa Solos, 2009. 627p. 
